\title{
Late results of oesophageal and oesophagogastric resection in the treatment of oesophageal cancer
}

\author{
A. S. WARD and J. LEIGH COLLIS
}

Queen Elizabeth Hospital, Birmingham

\begin{abstract}
Oesophageal resection with oesophagogastric anastomosis is said to be followed by severe oesophagitis. Little is known, however, of the late results of this technique in patients with oesophageal carcinoma and the present communication records our experience with 23 long-term survivors. Except for one patient with recurrent carcinoma, all were in good health and taking a normal diet. Loss of weight, which is a normal sequel to oesophagogastric resection, was prevented by inserting two extra meals a day. Anaemia was not a problem and there was no evidence of vitamin $B_{12}$ or folate deficiency. None of the patients had any symptoms of oesophagitis, though all exhibited free reflux on recumbency. After operation patients are advised to sleep propped up and to avoid stooping or lying flat. These measures are thought to be largely responsible for the absence of oesophagitis in our series. Five patients were achlorhydric and 10 hypochlorhydric in response to intravenous pentagastrin $(6 \mu \mathrm{g} / \mathrm{kg}$ per hour). Mean basal output was $0.6 \mathrm{mEq} / \mathrm{hour}$ and mean maximal output $8.8 \mathrm{mEq} /$ hour.
\end{abstract}

Resection of part of the oesophagus, with or without upper partial gastrectomy, is an essential feature in the treatment of oesophageal cancer. Although there is general agreement on this point, there is considerable diversity of opinion on the most satisfactory method of restoring alimentary continuity. Oesophagogastrostomy is the simplest and most direct method but is said to be attended by a high incidence of oesophagitis and stricture formation (Allison and Borrie, 1949; Ripley, Olsen, and Kirklin, 1952). In view of these difficulties others have preferred to use a Roux loop oesophagojejunostomy with gastric exclusion (Allison and Da Silva, 1953), an interposed jejunal loop (Robertson and Sarjeant, 1950; Allison, Wooler, and Gunning, 1957) or a colon graft (Sherman, Mahoney, Dale, and Stabins, 1955 ; Montenegro and Cutait, 1958; Belsey, 1965). Attempts have also been made to produce a valvelike effect at the oesophagogastric junction (Watkins, Prevedel, and Harper, 1954 ; Pearson, Henderson, and Parrish, 1969). It is our belief, however, that the problems associated with oesophagogastrostomy have been greatly overemphasized in the past. Not only is it relatively quick and simple but in carcinoma patients, at least, it appears to be free of troublesome late complications. This paper describes the late results in a group of patients followed up for several years after resection for carcinoma.

\section{MATERIAL AND METHODS}

Twenty-three patients were selected from the followup clinic. Selection was based on two criteria only: agreement on the part of the patient to attend for tests, and an interval after operation of at least one year. There were 16 men and 7 women and the mean age was 61 years (range 49 to 74 years). The average interval between operation and investigation was 5 years 4 months (range 1 to 15 years). Four patients presented with a carcinoma of the middle third of the oesophagus, 7 patients had a lower third growth and 12 had a carcinoma of the cardia. The histology was a squamous-cell carcinoma in 10 patients and an adenocarcinoma in 13 cases. Lower oesophageal resection only was performed in 4 patients while distal resection was combined with upper partial gastrectomy in the other 19 patients. Reconstruction was achieved by mediastinal oesophagogastrostomy in all cases.

Two features are emphasized in the post-operative management of these patients. Firstly, appetite is easily satisfied so that extra meals must be taken to prevent loss of weight. These meals can be conveniently inserted at mid-morning and evening. Secondly, excision of the cardia and creation of a new oesophagogastric junction within the chest renders patients susceptible to reflux. They are therefore instructed to sleep propped up against a bed wedge during the night and to avoid stooping or lying flat during the day. These precautions were being strictly observed by all the patients in the study. 
Four aspects were investigated in each patient. Firstly, clinical features of a general and specific nature were recorded. General condition, food intake and weight were noted together with the occurrence of heartburn, regurgitation, retrosternal pain and dysphagia. Particular attention was paid to the success or otherwise of the bed wedge in preventing nocturnal reflux.

Secondly, barium swallow was carried out in 18 of the 23 patients. The size, site and appearance of the anastomosis were noted together with the speed of gastric emptying and ease of gastro-oesophageal reflux.

The third aspect of the investigation concerned the haematological state. Haemoglobin, blood count, serum iron and iron binding capacity, vitamin $\mathbf{B}_{12}$ and folate levels were determined in all patients.

Finally, gastric analysis was performed in all patients. After an overnight fast a nasogastric tube was passed through the nose into the gastric antrum. Sampling was by continuous suction and 10-minute collections were made throughout. The basal secretory rate was measured for one hour and then a constant stimulus was applied by means of a continuous intravenous infusion of pentagastrin at a rate of $6 \mu \mathrm{g} / \mathrm{kg}$ per hour. Gastric collection was continued for a further hour after commencing the infusion. The volume and hydrogen ion concentration of each sample were measured and in addition the presence and approximate degree of bile staining was noted. Maximal acid output was calculated from the three highest 10-minute collections after commencing infusion and the result was expressed in milliequivalents per hour.
RESULTS

The results have been set out under four headings :

1. Clinical FEATURES Twenty-two of the 23 patients were in good health and had gained $\overparen{\mathbb{D}}$ weight after operation. These patients had all maintained their weight over succeeding years. One patient who was subsequently found to have recurrent carcinoma had recently lost weight. All $\overrightarrow{\vec{F}}$ the patients were able to swallow comfortably from the time of operation onwards and all were $\overrightarrow{\vec{x}}$ taking a normal or near normal diet. Heartburn. acid regurgitation and retrosternal pain were not encountered and it seems reasonable to assume $\overrightarrow{\overrightarrow{.}}$ that significant oesophagitis was absent in our 0 patients. One patient experienced a small haematemesis 12 months after operation. Oesophagoscopy and barium swallow at that time failed to reveal either the cause or the site of the bleeding.

All the patients were s'eeping with the bed $\vec{\theta}$ wedge in place ; 20 stayed propped up throughout $\rightarrow$ the night but 3 patients were aware of occasionally slipping down to an almost horizontal position for brief periods. One patient complained of a sense of fluid coming up into the throat on these occasions, though there was no associated pain or heartburn. The other two patients had no symptoms for the short time they were recumbent.

2. BARIUM SWALLOW Eighteen patients were examined by barium swallow. The anastomosis

T A B L E

GASTRIC ACID OUTPUT IN 23 PATIENTS FOLLOWING OESOPHAGEAL AND OESOPHAGOGASTRIC RESECTION FOR CARCINOMA OF OESOPHAGUS

\begin{tabular}{|c|c|c|c|c|c|c|c|c|c|}
\hline \multirow{2}{*}{ Patient } & \multirow{2}{*}{ Sex } & \multirow{2}{*}{$\begin{array}{l}\text { Age } \\
\text { at } \text { Test }\end{array}$} & \multirow{2}{*}{$\begin{array}{c}\text { Year of } \\
\text { Operation }\end{array}$} & \multirow{2}{*}{$\begin{array}{c}\text { Site of } \\
\text { Carcinoma }\end{array}$} & \multirow[b]{2}{*}{ Histology } & \multicolumn{2}{|c|}{ Operative Procedure } & \multicolumn{2}{|c|}{ Acid Output (mEq/hr) } \\
\hline & & & & & & Resection & $\begin{array}{c}\text { Partial } \\
\text { Gastrectomy }\end{array}$ & Basal & Maximal \\
\hline $\begin{array}{l}\text { G.N. } \\
\text { L.K. } \\
\text { A.W. } \\
\text { W.B. } \\
\text { R.P. } \\
\text { G.M. }\end{array}$ & $\begin{array}{l}\mathbf{F} \\
\mathbf{F} \\
\mathbf{M} \\
\mathbf{M} \\
\mathbf{M} \\
\mathbf{M}\end{array}$ & $\begin{array}{l}74 \\
66 \\
54 \\
51 \\
56 \\
54\end{array}$ & $\begin{array}{l}1961 \\
1965 \\
1966 \\
1968 \\
1955 \\
1958\end{array}$ & $\begin{array}{c}\text { Middle third } \\
\text {," } \\
\text { Lower third } \\
\text { ", }\end{array}$ & $\begin{array}{c}\text { Squamous-cell } \\
, \\
\Longrightarrow \\
\text { Adeno- } \\
\text { carcinoma }\end{array}$ & $\begin{array}{l}+ \\
+ \\
+ \\
+ \\
+ \\
+\end{array}$ & $\begin{array}{l}- \\
\overline{-} \\
\overline{-} \\
+ \\
+\end{array}$ & $\begin{array}{l}0 \cdot 3 \\
0 \cdot 7 \\
\mathrm{Nil} \\
1 \cdot 3 \\
\mathrm{Nil} \\
2 \cdot 2\end{array}$ & $\begin{array}{l}12 \cdot 2 \\
2 \cdot 9 \\
\mathrm{Nil} \\
9 \cdot 6 \\
\mathrm{Nil} \\
9 \cdot 7\end{array}$ \\
\hline $\begin{array}{l}\text { B.W. } \\
\text { R.C. } \\
\text { K.L. } \\
\text { N.K. } \\
\text { A.T. } \\
\text { H.B. }\end{array}$ & $\begin{array}{l}\mathbf{M} \\
\mathbf{F} \\
\mathbf{F} \\
\mathbf{M} \\
\mathbf{M} \\
\mathbf{M}\end{array}$ & $\begin{array}{l}49 \\
70 \\
62 \\
52 \\
62 \\
73\end{array}$ & $\begin{array}{l}1960 \\
1966 \\
1968 \\
1968 \\
1969 \\
1957\end{array}$ & $\begin{array}{c}\ddot{\prime} \\
\ddot{"} \\
\text { Cärdia }\end{array}$ & $\begin{array}{c}\text { Squamous-cell } \\
, " \\
\text { Adeno- } \\
\text { carcinoma }\end{array}$ & $\begin{array}{l}+ \\
+ \\
+ \\
+ \\
+ \\
+\end{array}$ & $\begin{array}{l}+ \\
+ \\
+ \\
+ \\
+ \\
+\end{array}$ & $\begin{array}{l}0.5 \\
\mathrm{Nil} \\
\mathrm{Nil} \\
1.7 \\
\mathrm{Nil} \\
1.6\end{array}$ & $\begin{array}{r}32 \cdot 2 \\
\mathrm{Nil} \\
\mathrm{Nil} \\
23 \cdot 8 \\
1 \cdot 0 \\
16 \cdot 6\end{array}$ \\
\hline $\begin{array}{l}\text { N.R. } \\
\text { R.T. } \\
\text { C.S. } \\
\text { A.L. }\end{array}$ & $\begin{array}{l}\mathbf{M} \\
\mathbf{M} \\
\mathbf{M} \\
\mathbf{F}\end{array}$ & $\begin{array}{l}64 \\
51 \\
68 \\
71\end{array}$ & $\begin{array}{l}1958 \\
1961 \\
1965 \\
1966\end{array}$ & $\begin{array}{l}\text { ", } \\
\text { ". }\end{array}$ & $\begin{array}{c}\text { Squamous-cell } \\
\text { Adeno- } \\
\text { carcinoma }\end{array}$ & $\begin{array}{l}+ \\
+ \\
+ \\
+\end{array}$ & $\begin{array}{l}+ \\
+ \\
+ \\
+\end{array}$ & $\begin{array}{l}1 \cdot 8 \\
\mathrm{Nil} \\
\mathrm{Nil} \\
\mathrm{Nil}\end{array}$ & $\begin{array}{r}14 \cdot 4 \\
12 \cdot 6 \\
18 \cdot 2 \\
\text { Nil }\end{array}$ \\
\hline $\begin{array}{l}\text { A.H. } \\
\text { J.B. } \\
\text { E.S. } \\
\text { W.H. } \\
\text { D.L. } \\
\text { A.M. } \\
\text { D.N. }\end{array}$ & $\begin{array}{l}\mathbf{M} \\
\mathbf{M} \\
\mathbf{F} \\
\mathbf{M} \\
\mathbf{M} \\
\mathbf{M} \\
\mathbf{F}\end{array}$ & $\begin{array}{l}53 \\
56 \\
68 \\
59 \\
67 \\
68 \\
52\end{array}$ & $\begin{array}{l}1966 \\
1966 \\
1968 \\
1969 \\
1969 \\
1969 \\
1969\end{array}$ & $\begin{array}{l}\text { ", } \\
\text {," } \\
\text { ", }\end{array}$ & $\begin{array}{l}\text { ", } \\
\text { ", } \\
, " \\
\text { ", }\end{array}$ & $\begin{array}{l}+ \\
+ \\
+ \\
+ \\
+ \\
+ \\
+\end{array}$ & $\begin{array}{l}+ \\
+ \\
+ \\
+ \\
+ \\
+ \\
+\end{array}$ & $\begin{array}{l}\mathrm{Nil} \\
2 \cdot 5 \\
\mathrm{Nil} \\
\mathrm{Nil} \\
1 \cdot 0 \\
0 \cdot 3 \\
\mathrm{Nil}\end{array}$ & $\begin{array}{r}2 \cdot 0 \\
29 \cdot 0 \\
5 \cdot 0 \\
1 \cdot 3 \\
9 \cdot 1 \\
1 \cdot 5 \\
2 \cdot 1\end{array}$ \\
\hline
\end{tabular}


appeared satisfactory and emptying of the gastric remnant was rapid in all cases. Tilting the patient into a horizontal position produced free reflux of barium into the oesophagus in every case. A similar examination had been undertaken in the immediate post-operative period with identical results.

3. HAEMATOlogical inVEstigation Haemoglobin varied between $79 \%$ and $108 \%$ and the mean for the group was $98 \%$. One patient with a haemoglobin of $79 \%$ had a low serum iron, raised iron-binding capacity and both microcytosis and hypochromia on the blood film. Apart from this case there were no haematological deficits; serum $B_{12}$ and folate levels in particular were all normal.

4. GASTRIC ANALYSIS The results of gastric analysis are shown in the accompanying Table. The most striking feature is the occurrence of pentagastrin-fast ach'orhydria in 5 patients and hypochlorhydria in a further 10 cases. Normal basal acid output for this laboratory is $1-3 \mathrm{mEq} /$ hour and maximal output $10-35 \mathrm{mEq} /$ hour after pentagastrin; these levels for both readings were attained in only 4 of our patients. Mean basal output for the entire group was $0.6 \mathrm{mEq} /$ hour and mean maximal output $8.8 \mathrm{mEq} /$ hour. There was no relationship between gastric secretion and the site or type of tumour though the preponderance of patients with carcinoma of the cardia makes useful comparisons difficult. The length of time after operation and the extent of resection likewise did not appear to influence gastric acid output.

Bile staining of a mild degree was observed in one patient; all samples from both basal and stimulatory periods were affected.

\section{DISCUSSION}

There have been few long-term studies of patients surviving oesophageal resection for carcinoma. This is, of course, directly related to the high recurrence rate and poor long-term prognosis (Collis, 1957; Miller, 1962). The results of this study indicate that the quality of life in the survivors is, in fact, surprisingly good after resection with oesophagogastrostomy. All our patients were in good health at the time of investigation and had gained weight after operation. Food intake tends to be reduced after resection because of the vertical position of the stomach, the mediastinal closure around the oesophagogastric tube and the reduction in capacity due to partial gastrectomy.
There is a natural tendency to lose weight and at least two extra meals a day must be taken to maintain nutrition. This precaution was proving successful in our patients and all were taking a normal or near normal diet without difficulty.

Apart from one patient with iron deficienc'y there was no evidence of nutritional anaemia in this series. The finding of normal serum $B_{12}$ levels was of particular importance in eliminating pernicious anaemia as a cause of achlorhydria.

Oesophagitis was not a problem. There was no significant heartburn, regurgitation, pain or dysphagia in any of the patients at any time after operation. In one case there was a history of haematemesis 12 months after operation, but investigations including oesophagoscopy and barium meal were normal. It was not felt justifiable to oesophagoscope the other asymptomatic patients and absence of oesophagitis is based on subjective evidence alone. Previous experience with hiatus hernia patients, however, has indicated that oesophagitis is nearly always associated with clear-cut symptoms (Ward, Wright, and Collis, 1970).

The absence of oesophagitis in the present study conforms with our experience from over 400 resections. This is at variance with most other reports and requires further comment. All patients are susceptible to reflux following resection and oesophagogastrostomy: free reflux was observed on barium swallow in the recumbent position in our patients both immediately after operation and again several years later. Two special post-operative measures have been adopted to guard against the effects of this reflux. Firstly, patients are advised to avoid bending or lying flat for any length of time during the day. Secondly, they are instructed to sleep propped up against a bed wedge during the night. This precaution is considered to be particularly important and nocturnal reflux was almost completely prevented. Allison and Borrie (1949) mention propping up patients after resection but, apart from this report, there is little evidence that others have adopted a similar regime. Failure to institute an effective postural regime after operation may account for the deve'opment of oesophagitis in other series. Definite conclusions on this point cannot be reached because of lack of a control series in our own patients.

Oesophageal resection may be necessary for peptic stricture and ulceration in addition to carcinoma and the evidence so far suggests that oesophagitis may be even more of a problem in these groups (Barrett and Franklin, 1949). This 
is at present under investigation: it is possible that an effective postural regime may protect against post-operative oesophagitis in benign conditions in the same way as it appears to do in the malignant cases described.

In contrast to our experience and that of Miller (1962), most authors have reported a high incidence of oesophagitis after oesophagogastrostomy (Allison and Borrie, 1949 ; Ripley et al., 1952 ; Watkins et al., 1954). Alternative methods of reconstruction have been employed but these are not without their own unfortunate sequelae. Thus the problems of a jejunal loop include precarious blood supply, reduction in food intake, alkaline oesophagitis and possible leakage from one or other of the suture lines. A colon graft may fail to relieve completely dysphagia due to slow emptying and is also subjected to ischaemia and anastomotic leak. On the other hand, the blood supply of the stomach is good, dysphagia is effectively relieved and there is only one anastomotic suture line so that the chances of leakage are reduced. Procedures designed to create a valve at an oesophagogastric anastomosis increase operation time and do not appear to protect completely against oesophagitis (Pearson et al., 1969). Many patients with oesophageal malignancy are elderly and undernourished, and long, unnecessarily complicated operations with attendant post-operative morbidity are poorly tolerated. Oesophagogastrostomy is quick, simple and safe and provides immediate symptomatic relief. In special circumstances, such as after a previous partial gastrectomy or where there is fibrosis in and around the duodenum, it may be impossible to use the stomach for anastomosis and the procedure of choice may then be total gastrectomy with Roux-en-Y oesophagojejunostomy or a colon graft.

The results of gastric analysis show that achlorhydria and hypochlorhydria are common after resection for carcinoma. This is, of course, to be expected in view of the total vagotomy which inevitably accompanies oesophageal resection. In addition, most resections include an upper partial gastrectomy which further reduces acid output. Acidity may be low even before operation due to starvation or age of the patient or because many growths arise in the stomach where there is a specific association with achlorhydria.

There is, unfortunately, little information on gastric acidity in series where oesophagitis has been a problem. Allison (1948) described the results of histamine stimulation in four patients surviving resection and oesophagogastrostomy for carcinoma. Two of his cases were achlorhydric and one was hypochlorhydric ; all, however, had severe oesophagitis with ulceration at the time of testing. Ripley et al. (1952) also described acid output in two patients who developed oesophagitis after oesophagogastrostomy: both had histaminefast achlorhydria. It seems likely, therefore, that the great majority of patients who survive resection for carcinoma are either hypochlorhydric or achlorhydric and that patients with oesophagitis do not differ from those without inflammatory change in this respect. Theories attributing oesophagitis to acid reflux cannot be correct. A few patients may retain normal gastric acidity after operation, as in four of our cases, and reflux of acid could then be a significant factor. The number of such patients, however, is very small and does not correspond with the almost universal incidence of oesophagitis reported elsewhere.

Reflux of bile and alkaline juice has recently been suggested as a possible factor in the development of oesophagitis (Cole, 1968). These agents are certainly capable of producing a severe inflammatory reaction in the oesophagus, both in animals (Cross and Wangensteen, 1951 ; Redo, Barnes, and De La Sierra, 1959) and in man (McKeown, 1958 ; Cox, 1961 ; Holt and Large, 1961). Whether the oesophagus is ever exposed to appreciable bile or alkaline reflux after resection is unknown but it seems unlikely. Bile was constantly present in the gastric aspirate in one of our patients and significant bile reflux could perhaps have occurred in this case. Total vagotomy is an inevitable accompaniment of oesophageal resection and in some series a pyloroplasty has been carried out in order to prevent gastric stasis (DeBakey and Cooley, 1953 ; Pearson et al., 1969). This addition allows bile and duodenal contents to enter the stomach in increased amounts and might therefore be expected to favour the development of oesophagitis. In fact, oesophagitis has been observed after resec- $\frac{D}{0}$ tion with the same frequency in patients with pyloroplasty (DeBakey and Cooley, 1953) as in $\widetilde{N}$ those not subject to this procedure (Ripley et al., $N$ 1952). Moreover, pyloroplasty has been widely $N$ used with good results in the treatment of estab- $\omega$ lished oesophagitis in hiatus hernia patients (Bur-? ford and Lischer, 1956). Bile and alkaline reflux $\odot$ is therefore unlikely to be important in the $\stackrel{\oplus}{\Phi}$ development of post-operative oesophagitis.

Oesophageal resection does not appear to be $\frac{T}{T}$ followed by gastric stasis despite total vagotomy, $\stackrel{\circ}{\mathbb{D}}$ and drainage procedures are, in fact, unnecessary $\frac{?}{\mathbb{Q}}$ (Collis, 1965). Rapid emptying of the gastric $\varrho$ remnant can be demonstrated on barium swallow? both immediately after operation and again $\delta$ 
several years later. The lesser curve of the stomach and the first part of the duodenum tend to become straightened out following anastomosis in the chest and rapid emptying may be due to a gravity effect. Any tendency to post-operative distension is further reduced by closure of the mediastinum around the oesophagogastric tube.

The assistance of Miss Sheila Nutter, technician in the Gastro-intestinal Laboratory, is gratefully acknowledged.

\section{REFERENCES}

Allison, P. R. (1948). Peptic ulcer of the oesophagus. Thorax, 3, 20. and Borrie, J. (1949). The treatment of malignant obstruction of the cardia. Brit. J. Surg., 37, 1.

and Da Silva, L. T. (1953). The Roux loop. Brit. J. Surg., 41, 173.

Wooler, G. H., and Gunning, A. J. (1957). Esophagojejunogastrostomy. J. thorac. Surg., 33, 738.

Barrett, N. R., and Franklin, R. H. (1949). Concerning the unfavourable late results of certain operations performed in the treatment of cardiospasm. Brit. J. Surg., 37, 194.

Belsey, R. (1965). Reconstruction of the esophagus with left colon. J. thorac. cardiovasc. Surg., 49, 33.

Burford, T. H., and Lischer, C. E. (1956). Treatment of short esophageal hernia with esophagitis by Finney pyloroplasty. Ann. Surg., 144, 647.

Cole, G. J. (1968). Oesophagitis. Hosp. Med., 2, 1321.

Collis, J. L. (1957). Carcinoma of the oesophagus. The case for surgical excision. Lancet, 2, 613.

(1965). Tumours of the Oesophagus in Clinical Surgery, Vol. 5 , Edited by Rob, C., and Smith, R. Butterworths, London.
Cox, K. R. (1961). Oesophageal stricture after partial gastrectomy. Brit. J. Surg., 49, 307.

Cross, F. S., and Wangensteen, O. H. (1951). Role of bile and pancreatic juice in production of esophageal erosions and anemia. Proc. Soc. exp. Biol. (N.Y.), 77, 862.

DeBakey, M. E., and Cooley, D. A. (1953). Palliative resection for carcinoma of the esophagus. Arch. Surg., 66, 781.

Holt, C. J., and Large, A. M. (1961). Surgical management of reflux esophagitis. Ann. Surg., 153, 555.

McKeown, K. C. (1958). Oesophageal stenosis after partial gastrectomy. Brit. med. J., 2, 819.

Miller, C. (1962). Carcinoma of thoracic oesophagus and cardia. A review of $\mathbf{4 0 5}$ cases. Brit. J. Surg., 49, 507.

Montenegro, E. B., and Cutait, D. E. (1958). Construction of a new esophagus by means of the transverse colon and its application for caustic atresia, carcinoma, and varices of the esophagus. Report of 26 cases. Surgery, 44, 785.

Pearson, F. G., Henderson, R. D., and Parrish, R. M. (1969). An operative technique for the control of reflux following esophagogastrostomy. J. thorac. cardiovasc. Surg., 58, 668.

Redo, S. F., Barnes, W. A., and De La Sierra, A. O. (1959). Perfusion of the canine esophagus with secretions of the upper gastrointestinal tract. Ann. Surg., 149, 556.

Ripley, H. R., Olsen, A. M., and Kirklin, J. W. (1952). Esophagitis after esophago-gastric anastomosis. Surgery, $32,1$.

Robertson, R., and Sarjeant, T. R. (1950). Reconstruction of esophagus. J. thorac. Surg., 20, 689.

Sherman, C. D., Mahoney, E. B., Dale, W. A., and Stabins, S. J. (1955). Intrathoracic transplantation of the right colon for esophageal reconstruction. Cancer (Philad.), 8, 1198.

Ward, A. S., Wright, D. H., and Collis, J. L. (1970). The assessment of oesophagitis in hiatus hernia patients. Thorax 25,568 .

Watkins, D. H., Prevedel, A., and Harper, F. R. (1954). A method of preventing peptic esophagitis following esophagogastrostomy.
J. thorac. Surg., 28, 367. 